\section{Should Pharmacy Technician Managers Be Responsible for the Drug Distribution System within Hospital Pharmacy Departments?}

\section{THE "PRO" SIDE}

The Blueprint for Pharmacy calls for pharmacists and technicians to work to their full scope of practice, which includes an expanded role for pharmacy technicians. More specifically, the Blueprint calls for "care [to be] provided ... in a collaborative manner where pharmacists focus on medication management and patient health outcomes, and pharmacy technicians focus on drug distribution." In addition, the Canadian Society of Hospital Pharmacists states that supervisory and/or management roles may be delegated to pharmacy technicians. ${ }^{2}$ Therefore, the time has come to engage pharmacy technicians as managers of the drug distribution system within hospital pharmacy departments.

Drug distribution tasks are already being performed by pharmacy technicians. In fact, as the role of technicians expands, many of these tasks are also verified by technicians rather than by pharmacists. Within the pharmacy department, pharmacy technicians often maintain automated drug distribution systems and processes. As the complexity of these systems and processes grows, it is important that managers understand them, to ensure continuity of service and appropriate drug delivery. If the day-to-day acts of drug distribution are the responsibility of pharmacy technicians, it would seem appropriate for pharmacy technicians to also manage these systems. As medication technologies, patient acuity, and the use of medications expand, the human resource needs of pharmacy technicians will also grow. Who better to manage this sector of the workforce from a human resources and operations perspective than a pharmacy technician manager?

Training for pharmacy technicians, provided by accredited colleges, already includes specific knowledge and skills related to management principles. ${ }^{3}$ Assuming management, administrative, and quality assurance responsibilities constitutes 1 of 7 educational outcomes for entry-to-practice programs for Canadian pharmacy technicians. ${ }^{4}$ Included within this management educational outcome is the management of operations, administrative activities, and finances within a practice environment. Several performance indicators, such as managing workflow, supervising personnel, preparing and maintaining records for legal purposes, maintaining policies and procedures, and taking on financial responsibilities, are described. These competencies provide a basic platform for managing the drug distribution system.

Managerial education and training are currently available to support pharmacy technicians in managing drug distribution systems. As with many health care professionals, including pharma- cists and nurses, pharmacy technicians can receive on-the-job managerial training. Many will already have experience with the drug distribution system that they will be managing and can receive workplace professional development through hospital or health region courses, interdepartmental courses, ${ }^{5}$ or courses in management at a postsecondary institution.

For those who argue that only pharmacists should manage the drug distribution system, it is important to recognize the current and future shortage of hospital pharmacist managers. ${ }^{6,7}$ Anticipated demographic changes in the Canadian pharmacy workforce over the next several years will exacerbate this pharmacist shortage. For example, in 2007/2008, Canadian hospital pharmacy managers estimated that $9 \%$ of all pharmacists and $16 \%$ of pharmacy managers were expected to retire in the next 5 years. ${ }^{6}$ The pharmacy technician workforce is generally younger than the pharmacist workforce, and retirement of "baby boomers" will be less of an issue for this group. ${ }^{6}$ As the pharmacists' clinical roles continue to expand, fewer are interested in leadership roles in the management of drug distribution. We can maximize the role of the pharmacist by having pharmacists provide professional and clinical expertise and judgement to pharmacy technician managers as the need arises for specific issues related to the drug distribution system, rather than having them serve as full-time pharmacist managers of that system.

Pharmacy technician managers can, and do, successfully manage drug distribution systems within Canadian hospital pharmacy departments. ${ }^{6}$ From an experience and knowledge perspective, they are well suited to manage these systems and the staff who work with them. They are appropriately trained in management skills and, when required and like many health care professionals who grow into leadership roles, can obtain the necessary education and experience in this area. As pharmacists expand their focus from drug distribution to providing direct patient care, it is necessary to rely on pharmacy technicians as managers of the drug distribution system. This is a role that pharmacy technicians are capable, willing, and ready to do.

\section{References}

1. Task Force on a Blueprint for Pharmacy. Blueprint for pharmacy: implementation plan. Ottawa (ON): Canadian Pharmacists Association; 2009 Sep [cited 2011 Feb 9]. Available from: www.pharmacists.ca/ content/about_cpha/whats_happening/cpha_in_action/pdf/Blueprint ImplementationPlan.pdf

2. Pharmacy technicians: guidelines on the delegation of functions to pharmacy technicians. Ottawa (ON): Canadian Society of Hospital Pharmacists; 2006.

3. Professional competencies for Canadian pharmacy technicians at entry to practice. Ottawa (ON): National Association of Pharmacy Regulatory Authorities; 2007 Sep [cited 2011 Feb 9]. Available from: http://napra.ca/Content_Files/Files/Professional_Competencies_for_ Canadian_Pharmacy_Technicians2007.pdf 
4. Educational outcomes for pharmacy technician programs in Canada. Ottawa (ON): Canadian Pharmacy Technician Educators Association; 2007 Mar [cited 2011 Feb 9]. Available from: www.cptea.ca/private_pgs/ EducationalOutcomesMar2007.pdf

5. Woloschuk DMM, Raymond CB. Development of a supervisory skills course for hospital pharmacy workplaces. Can J Hosp Pharm 2010; 63(4):295-303.

6. Babiach M. Human resources. In: Babich M, Bussières JF, Hall KW, Harding J, Johnson N, Lefebvre P, et al., editors. Hospital pharmacy in Canada 2007/2008 report. p. 42-52. Available from: www.lillyhospitalsurvey.cal hpc2/content/2008_report/humanresources.pdf

7. CSHP Hospital Pharmacy Management Task Force. Planning for hospital pharmacy management, now and in the future. Can J Hosp Pharm 2008;61(5):374-384.

Colette B Raymond, PharmD, MSc, ACPR

Staff Development/Practice Evaluation Pharmacist

\section{Christina E Santos}

Pharmacy Technician Manager

Purchasing, Warehouse and Financial Systems

Cenzina Caligiuri, BScPharm

Regional Pharmacy Manager

Parenteral Drug Distribution Systems

Department of Pharmaceutical Services

Health Sciences Centre Hospital

Winnipeg Regional Health Authority

Winnipeg, Manitoba

\section{THE “CON" SIDE}

At first glance, it seems appropriate to expand the role of pharmacy technician managers to include responsibility for managing the drug distribution system within hospital pharmacy departments. However, doing so may be premature, as there are many questions to be addressed before we move in that direction: Does the pharmacy profession support the concept of technicians taking on this expanded role? Can health care organizations accommodate the change? Are pharmacists willing to support and collaborate with technicians? Are pharmacy technicians equipped to fulfill those responsibilities? In short, are we ready? This question of readiness - of organizations, systems, and staff - must be carefully considered if we are to ensure an effective and safe handover of responsibilities.

Management of the drug distribution system, if performed appropriately, is expected to have the following major outcomes:

- Competent staff and resources are available in the workplace.

- Patients' medication needs are met in a timely and efficient manner.

- Medication systems and processes are based on best practices and adhere to accepted standards of quality and patient safety.

- Health care workers are informed of major medicationrelated issues as they arise.

- Pharmacy technicians and pharmacists work effectively within teams.

- Customer needs are assessed regularly, and systems are designed to meet those needs.

- Policies and procedures are applied consistently across sites.
- Accurate workload and outcome data are readily accessible to support management and strategic decision-making.

- The working environment is safe.

Our professional associations support a judicious use of human resources. At the recent Pharmacy Practice Model Initiative summit, presented by the American Society of HealthSystem Pharmacists (ASHP), participants supported the concepts that pharmacy technicians with appropriate education, training, and credentials could be used much more extensively to free pharmacists from drug distribution activities and that all distributive functions not requiring clinical judgement should be assigned to technicians. ${ }^{1}$

The Canadian Society of Hospital Pharmacists (CSHP) has also embraced the idea of an expanded role for pharmacy technicians in the distribution process and has outlined supervisory and management functions for technicians in its Guidelines on the Delegation of Functions to Pharmacy Technicians. ${ }^{2}$

Both organizations, however, imply that some distribution activities require clinical judgement. Therefore, we must ask whether all distribution system activities can be safely managed and all associated staff effectively led by a pharmacy technician manager.

There is a need to more clearly define the scope of the management responsibilities related to drug distribution that could be fulfilled by pharmacy technician managers and the core competencies that candidates should possess. Doing so would align with proposed key actions related to pharmacy human resources and education found in the Blueprint for Pharmacy: The Vision for Pharmacy. ${ }^{3}$

No matter the scope of technicians' activities, associations such as the ASHP and the CSHP specify that technicians with management responsibilities should report to a pharmacist for direction and supervision. ${ }^{1,2}$ Organizations with a nonpharmacist director would require a reporting structure in which the technician manager reports to a pharmacist, who would ultimately be responsible for the drug distribution system.

As technicians take on increased management responsibilities in unionized organizations within the health care system, their positions may have to be reclassified or new nonbargaining positions created. Clearly defined core competencies for these positions will also be essential, to assist in the selection of suitable candidates and to prevent misunderstandings related to the required qualifications.

Committees, working groups, and teams within the health care system may have to revise their terms of reference to include pharmacy technician managers as members and to authorize them to make decisions as pharmacy representatives.

Pharmacy managers will have to be open to transferring some decision-making authority to technician managers and must also be willing to facilitate the transition of individual technicians from staff positions to management positions with expanded responsibilities.

It may be possible to attract pharmacy technicians to take on new management responsibilities, but to retain them in these roles, it will be essential to provide support to maximize their professional satisfaction. Helpful recommendations in a recent article by the CSHP Hospital Pharmacy Management Task Force ${ }^{4}$ could be expanded to include technicians. Technicians 
who demonstrate leadership qualities would benefit from performance management that promotes and supports the development of competencies related to management roles.

Changes in the organizational structure of hospitals and of pharmacy departments have led to the reduction or elimination of entry-level management positions for pharmacists. ${ }^{4.5}$ Will designating pharmacy technicians to be responsible for the drug distribution system further erode opportunities to prepare pharmacists for managerial roles? If so, alternative development opportunities for pharmacists will need to be considered. Furthermore, will pharmacists be fully cooperative in reporting to the pharmacy technician managers who oversee their distributive activities? Given the differences in beliefs and attitudes that may be present among colleagues, maintaining respectful working relationships will be essential.

Finally, technicians do not receive extensive management training in their program curricula, nor do they have easy access to management programs once in the workforce. Opportunities to acquire the knowledge and develop the skills required to effectively manage the drug distribution system would have to be created.

If pharmacy technicians are designated as managers of the drug distribution system, with minimal pharmacist involvement, tools such as the soon-to-be-published CSHP 2015 "Hit the Target" toolkit on unit-dose medication management systems would support them in their expanded role. A variety of similar tools would have to be gathered or developed. These would serve as the basis for a quality assurance program designed to ensure that delegated tasks are consistently performed at the expected level.

Technicians know the drug distribution system. They effectively perform tasks within that system on a daily basis, ensuring that patients have the medications they need, when they need them. Some technicians already fulfill supervisory and managerial responsibilities. To expand the role of those technicians or to attract other technicians to expanded management roles, it will be necessary to make sure that they receive adequate training and orientation and that their work is closely monitored, with provision of direction as needed. A medication distribution system that is managed by technicians and driven by technology will allow pharmacists to focus more fully on quality of care and patient safety. ${ }^{6}$

Are we ready to transfer responsibility for the drug distribution system to pharmacy technicians? It seems premature to go quickly down this path on a large scale. There are certainly success stories across the country, but little has been shared formally. We should encourage and facilitate sharing by "early adopters", so that others can become better informed and equipped to initiate the transition. Ultimately, we should proceed with caution to ensure a successful outcome.

\section{References}

1. Pharmacy Practice Model Initiative. Summit recommendations February 1, 2011. Bethesda (MD): American Society of Health-System Pharmacists; 2011 [cited 2011 Mar 15]. Available from: www.ashp.org/DocLibrary/ PPMI/Summit-Recommendations.aspx

2. Canadian Society of Hospital Pharmacists. Pharmacy technicians: guidelines on the delegation of functions to pharmacy technicians. Ottawa (ON): Canadian Society of Hospital Pharmacists; 2006 [cited 2011 Mar 15]. Available from: www.cshp.ca/productsServices/officialPublications/type_e.asp

3. Task Force on a Blueprint for Pharmacy. Blueprint for pharmacy: the vision for pharmacy. Ottawa (ON): Canadian Pharmacists Association; 2008 [cited 2011 Mar 15]. Available from: www.pharmacists.ca/content/ about_cpha/whats_happening/cpha_in_action/pdf/BlueprintVision.pdf

4. CSHP Hospital Pharmacy Management Task Force. Planning for hospital pharmacy management, now and in the future. Can J Hosp Pharm 2008; 61(5):374-384.

5. Musing ELS, Wong M, Jackson L, Lee J, Slote C. A focus on leadership: CSHP's 2007 national leadership survey. Can J Hosp Pharm 2008;61(1): 70-77.

6. Williams BS. Case study: A tech-check-tech pilot study in an academic medical center [presentation hand-out]. In: Advancing the pharmacy team: innovative roles for PTCB certified pharmacy technicians [symposium]; 2009 Dec 7; Las Vegas (NV). Bethesda (MD): American Society of HealthSystem Pharmacists; 2009 [cited 2011 Mar 15]. p. 37-46. Available from: www.ashpadvantage.com/podcasts/handouts/09201-handout.pdf

Julie Levesque, B Pharm

Horizon Health Network

Pharmacy

Moncton, Saint John, Fredericton, and Miramichi, New Brunswick

\begin{tabular}{lll}
\multicolumn{3}{c}{ Advertisers ' Index } \\
\hline & Ad Page & Prescribing Information \\
\hline Eli Lilly / Insulin & 179 & 225,226 \\
\hline Pfizer / Fragmin & 176 & $227-230$ \\
\hline Pharmaceutical Partners of Canada / Corporate & IFC & - \\
\hline Pharmaceutical Partners of Canada / Corporate & OBC & - \\
\hline Sandoz / Corporate & 174 & - \\
\hline
\end{tabular}

